\title{
Synthesis of Novel Benzamide- piperazine- sulfonamide Hybrids as Potential Anticancer Agents
}

\author{
B. Ramalingeswara Rao, ${ }^{1, *}$ Mohana Rao Katiki, ${ }^{1, *}$ Dileep Kommula, ${ }^{1, *}$ SaiShyam Narayanan, ${ }^{2}$ Ruby John Anto, ${ }^{2}$ M. S. R. Murty ${ }^{1}$
}

1 Medicinal Chemistry and Pharmacology Division, Discovery Laboratory, CSIR-Indian Institute of Chemical Technology, Uppal Road, Hyderabad-500007, India

2 Cancer Research Program, Division of Cancer Research, Rajiv Gandhi Centre for Biotechnology, Thycaud P.0, Kerala, Thiruvananthapuram-695014, India

*Authors' e-mail addresses: raamu79@gmail.com; mohanelr@gmail.com; dilip.kommula@gmail.com

RECEIVED: June 20, $2019 \star$ REVISED: September 29, $2019 \star$ ACCEPTED: September 30, 2019

Abstract: The synthesis of a series of substituted hippuric acid (2-benzamidoacetic acid) derivatives containing arylsulfonylpiperazine nucleus $(3 a-j, 4 a-j)$ is described. The compounds were synthesized by coupling hippuric/4-fluorohippuric acid with various arylsulfonylpiperazines using $\mathrm{N}$-(3-dimethylaminopropyl)-N-ethylcarbodiimide (EDCI). The structures of all the new compounds were confirmed by IR, NMR and MS spectral data. All the synthesized compounds have been evaluated for their in vitro cytotoxicity towards five human cancer cell lines of different origins viz. HeLa (Cervical), A549 (Lung), A375 (Skin), MD-AMB-231(Breast) and T98G (brain) and their IC 50 values were determined. Among the compounds tested, $3 \mathrm{~b}, 3 \mathrm{~d}, 3 \mathrm{~g}$, $4 \mathrm{c}$ and $4 \mathrm{e}$ displayed significant cytotoxic activity $\left(\mathrm{IC}_{50}=24.2-38.2 \mu \mathrm{M}\right)$. T98G was the most sensitive cell line towards the compounds studied followed by HeLa, A375, A549 and MD-AMB-231.

Keywords: arylsulfonylpiperazine, EDCl, anticancer, MTT assay.

\section{INTRODUCTION}

$\mathbf{N}$ OWADAYS, cancer has gradually become the leading disease-related cause of deaths of human population and is also a seriously threatening the health and life of humans for a long period. Among all the current therapeutic methods, chemotherapy still remains an important option for cancer treatment. ${ }^{[1-3]}$ However, the major hindrance to successful cancer chemotherapy is the development of drug and multidrug-resistance, in which cancer cells become simultaneously resistant to different structural types of chemotherapeutic agents and the development of novel anticancer drug. ${ }^{[4-6]}$

Therefore, there is a need of new approaches that are specifically designed to avoid these drawbacks. The discovery of novel effective anticancer agents with leading properties than the currently used and with an alternative mechanism of action is an important endeavor in medicinal chemistry. ${ }^{[7,8]}$ Thus it is necessary to attempt new chemical entities (NCE's) as potential chemotherapeutic agents with an alternative mechanism of action. Recent progress in the field of cell biology has resulted in small molecule kinase inhibitors that have been successfully introduced into the drug market as selective anticancer agents with lowered side effects. ${ }^{[9]}$ These findings provide new targets for anticancer drug design. In the design of new bioactive agents, the development of hybrid structures using a combination of two or more pharmacophores that have different mechanisms of action in the same molecule is the method of choice. These merged pharmacophores offer the possibility to overcome the current drug resistance and to reduce the appearance of new resistant strains. In addition, the strategy can also reduce unwanted side effects and may enhance biological potency.

Recently, amide derivatives received significant attention for their antitumor properties, especially the compounds which containing benzamide pharmacophore. The benzamide derivatives have been reported for their wide range of pharmacological activities including antitumor, ${ }^{[10]}$ histonedeacetylase inhibition, ${ }^{[11]}$ and CYP24A1 inhibitory activity. ${ }^{[12]}$ In addition to these activities some benazamide derivatives were used as HDAC inhibitors, ${ }^{[13]}$ glucokinaseactivators, ${ }^{[14]}$ and antiprion agents, ${ }^{[15]}$ etc. The promising bioactive diversity of this class of benzamide compounds urges us to synthesize and biologically evaluate a series of structural variants of benzamide derivatives. 
<smiles>COc1ccc(NS(=O)(=O)c2c(F)c(F)c(F)c(F)c2F)cc1F</smiles>

(Batabulin)<smiles>COc1ccc(S(=O)(=O)Nc2cccnc2Nc2ccc(O)cc2)cc1</smiles>

(ABT-751)<smiles>Cc1ccc(NS(=O)(=O)c2cccc(C#N)c2)c2[nH]cc(C#N)c12</smiles>

(E-7820)

Figure 1. Some of the biological active derivatives of arylsulfonamides.

Sulfonamides as an important class of pharmaceutical compounds exhibit a broad spectrum of biological activities $^{[16,17]}$ due to its relatively simple structure. These compounds provide a key polar alternative to the frequently used amides as a bioisosteric replacement. ${ }^{[18]}$ Sulfonamide derivatives also found to be potent cysteine protease inhibitors with possible extension of their therapeutic applications to Alzheimer's disease, arthritis and cancer. ${ }^{[19]}$ This group is also found in some potent new antimicrotubule agents such as 2-fluoro-1-methoxy-4-pentafluorophenylsulfonamidobenzene (T138067), [20] $\mathrm{N}$-[2-[(4-hydroxyphenyl)amino]-3-pyridinyl]-4-methoxybenzenesulfonamide (ABT-751) ${ }^{[21]}$ are shown in Figure 1.

Arylsulfonylpiperazines represent an important class of therapeutic agents which are good template for many different biological targets. In recent years, extensive research has been focused on developing novel piperazine derivatives to improve their biological activity. Piperazine bearing benzenesulfonyl group have been reported to showed anticancer, ${ }^{[22,23]}$ anti-allergic, ${ }^{[24]}$ neuronal nicotinicacetylcholine receptors, ${ }^{[25]}$ antibacterial, antiace-tylcholinesterase ${ }^{[26]}$ and selective covalent inhibitors of transglutaminase 2 for Huntington's disease ${ }^{[27]}$ activities. Furthermore, it was noticed that compound $\mathbf{1}$ as selective and orally bioavailable inhibitor (11ß-HSD1 inhibitors) with efficacy in a cynomolgus monkey ex vivo enzyme inhibition model. ${ }^{[28]}$ Also a high-throughput screening of a small molecule compound library utilizing a purified recombinant human enzyme identified compound 2 as a potent inhibitor of 11ß-HSD1 (Figure 2).

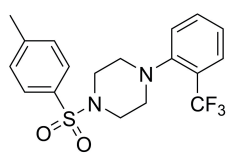

(1)

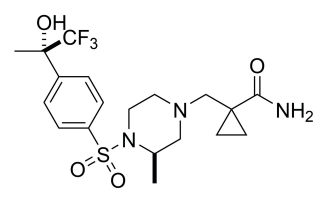

(2)
Figure 2. Chemical structure of representative arylsulfonylpiperazine.
The present study aimed to synthesize certain sulfonamide containing piperazine derivatives in order to explore their anticancer activity. In continuation of our research in the synthesis of bioactive heterocycles and their biological evaluation, ${ }^{[29-33]}$ we describe here, the synthesis of arylsulfonylpiperazine motif coupled with substituted benzamide derivatives to produce twenty new hybrid derivatives $\mathbf{3} \mathbf{a}-\mathbf{j}$ and $\mathbf{4 a - j}$ (Figure $\mathbf{3}$ ).

These newly synthesized compounds were evaluated for their cell growth inhibitory activities $\left(I_{50}\right)$ towards cultures of five different cancer cells using MTT assay method. Some of the compounds were able to induce good inhibitory activities against the proliferation on T98G cancer cell line, while some compounds showed moderate activity.

\section{EXPERIMENTAL}

All the reagents were obtained from commercial sources and used without purification. MTT was obtained from Sigma Chemicals (St. Louis, MO, USA). Melting points were determined on a Buchi capillary melting point apparatus. The NMR spectra were recorded on Varian Gemini and Bruker, Avance spectrometers. Chemical shifts $(\delta)$ are reportedin $\mathrm{ppm}$ relative to internal standard tetramethylsilane(TMS). IR spectra were recorded on Thermo Nicolet Nexus 670 FTIR spectrometer. The mass spectrum was recorded on Themo Scientific ExactiveOrbitrap mass spectrometer under Electron Spray Ionization (ESI) conditions preparing sample solutions in methanol. Elemental analyses were performed on Elemental VARIO EL elemental analyzer. Peak multiplicities are expressed as follows: s, singlet; $d$, doublet; t, triplet; $q$, quartet; bs, broad singlet; dd, doublet of doublet; $\mathrm{m}$, multiplet. Coupling constants $(\mathrm{J})$ are given in hertz $(\mathrm{Hz})$. Abbreviations are used as follows: DMF, N,Ndimethylformamide; DMSO, dimethyl sulfoxide; $\mathrm{EDCl}$, 1ethyl-3-[3-(dimethylamino)propyl]carbodiimide;HOBt, 1hydroxy benzotriazole. 


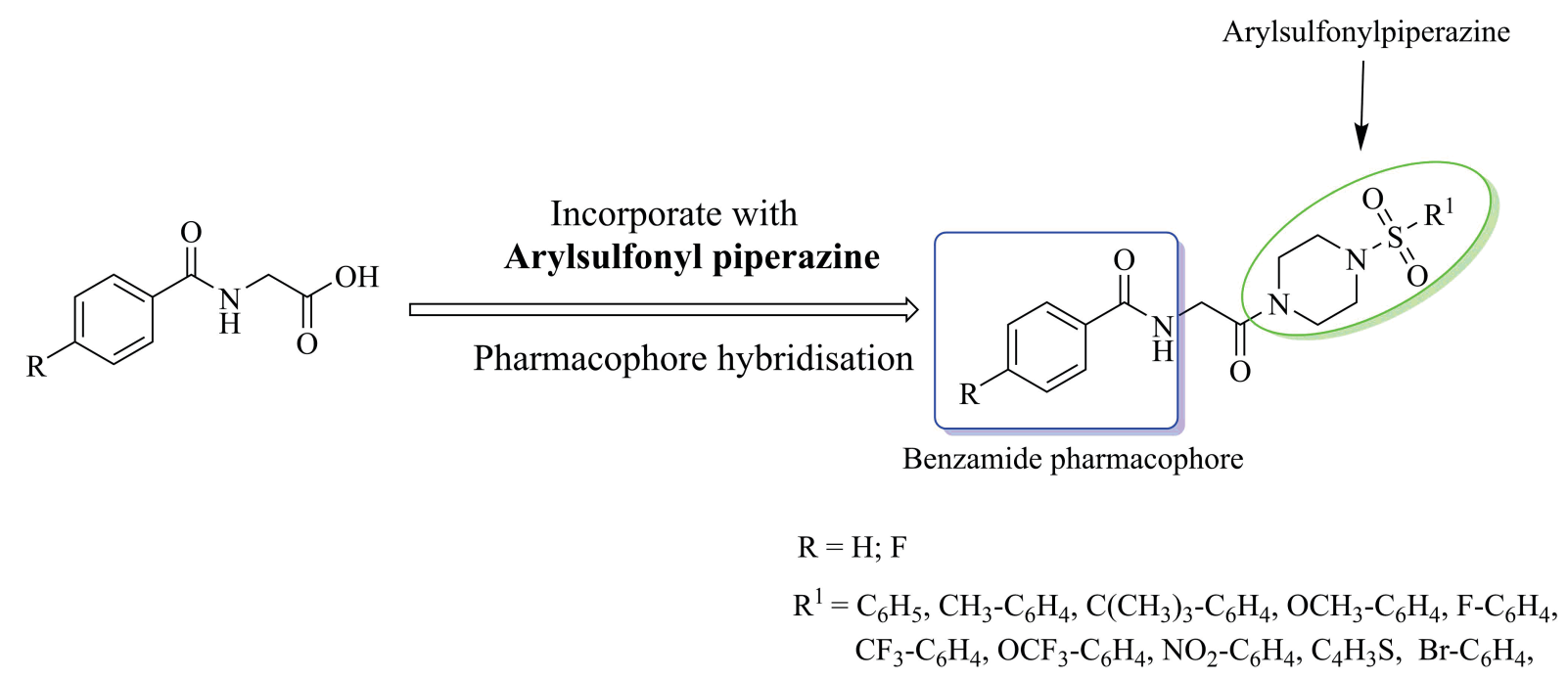

Figure 3. Rational concept to the synthesis of 4-substituted-N-(2-(4-((4-substitutedphenyl) sulfonyl) piperazin-1-yl)-2oxoethyl)benzamide.

General procedure for the synthesis of 2-(4-benzamido)/ 4-florobenzamido acetic acid (1a-b)

Glycine $(2 \mathrm{~g}, 0.026 \mathrm{~mol}, 1$ equiv) was dissolved in (1.6g $\mathrm{NaOH}$ in $20 \mathrm{~mL}$ water) $2 \mathrm{~N} \mathrm{NaOH}$ and taken in a round bottom flask, to that 4-fluorobenzoyl chloride in $\mathrm{CH}_{2} \mathrm{Cl}_{2}$ was added in portions. The reaction mixture $\tilde{v}$ was stirred for about four hours. After that to the reaction mixture hydrochloric acid was added till precipitate is formed. The obtained precipitate was filtered and washed with water.

\section{2-benzamidoacetic acid (1a) v}

IR (KBr) $\tilde{v} / \mathrm{cm}^{-1}: 1160,1253,1625$ (C=O), 1723, 2576, 2649, 2926, 3035, $3315(\mathrm{NH}) ;{ }^{1} \mathrm{H} \mathrm{NMR} \mathrm{(300} \mathrm{MHz,} \mathrm{CDCl}_{3}$ ) $\delta / \mathrm{ppm}$ : $3.86\left(\mathrm{~d}, 2 \mathrm{H}, J=3.3 \mathrm{~Hz}, \mathrm{NH}-\mathrm{CH}_{2}\right), 7.45$ (bs, $\left.1 \mathrm{H}, \mathrm{NH}\right), 7.54-$ $7.62(\mathrm{~m}, 2 \mathrm{H}, \mathrm{Ar}-\mathrm{H}), 7.88-8.03(\mathrm{~m}, 3 \mathrm{H}, \mathrm{Ar}-\mathrm{H}), 10.04$ (bs, $1 \mathrm{H}$, $\mathrm{COOH}) ;{ }^{13} \mathrm{C} \mathrm{NMR}\left(75 \mathrm{MHz}, \mathrm{CDCl}_{3}\right) \delta / \mathrm{ppm}: 42.1,127.6$, 129.5, 167.8, 169.5; ESI-MS m/z: 179 (M)+.

\section{4-florobenzamido acetic acid (1b)}

IR (KBr) ṽ/cm ${ }^{-1}: 3323(\mathrm{NH}), 3040,2933,2655,2571,1726$, 1639 (C=O), 1250, 1162; ${ }^{1} \mathrm{H}$ NMR (300 MHz, $\mathrm{CDCl}_{3}$ ) $\delta / \mathrm{ppm}$ : $3.88\left(\mathrm{~d}, 2 \mathrm{H}, J=3.9 \mathrm{~Hz}, \mathrm{NH}-\mathrm{CH}_{2}\right), 7.35-7.43(\mathrm{~m}, 2 \mathrm{H}, \mathrm{Ar}-\mathrm{H})$, 7.49 (bs, $1 \mathrm{H}, \mathrm{NH}), 7.98-8.15(\mathrm{~m}, 2 \mathrm{H}, \mathrm{Ar}-\mathrm{H}), 10.08$ (bs, $1 \mathrm{H}$, $\mathrm{COOH}) ;{ }^{13} \mathrm{C}$ NMR $\left(75 \mathrm{MHz}, \mathrm{CDCl}_{3}\right) \delta / \mathrm{ppm}: 42.3,126.9$, 129.3, 168.2, 171.4; ESI-MS m/z: $197(\mathrm{M})^{+}$.

General procedure for the synthesis of 1-((4-substitutedphenyl)sulfonyl)piperazine (2a-j)

4-substituted aryl sulfonyl chloride ( $10 \mathrm{mmol}, 1$ equiv) was added in one portion to a solution of piperazine $(60 \mathrm{mmol}$, 6 equiv) in $\mathrm{CH}_{2} \mathrm{Cl}_{2}(10 \mathrm{~mL})$ at $0{ }^{\circ} \mathrm{C}$. The reaction mixture was stirred at $0-10{ }^{\circ} \mathrm{C}$ for $30 \mathrm{~min}$. Dilute with more amount of $\mathrm{CH}_{2} \mathrm{Cl}_{2}(20 \mathrm{~mL})$, and removed the excess piperazine by the addition of saturated $\mathrm{NaHCO}_{3}$ (aq) $(50 \mathrm{~mL}$ ). Separate the organic layer washed with brine $(50 \mathrm{~mL})$, dried over $\mathrm{Na}_{2} \mathrm{SO}_{4}$ and concentrated in vacuo to provide crude product. The crude product was used directly or purified by crystallization using methanol to yield pure 1-((4-substitutedphenyl)sulfonyl)piperazine.

\section{1-(phenylsulfonyl)piperazine(2a)}

White solid. Yield: $88 \%$; IR (KBr) ṽ/cm ${ }^{-1}: 3324(\mathrm{NH}), 3095$, 3062, 2858, 2827; ${ }^{1} \mathrm{H}$ NMR (300 MHz, $\mathrm{CDCl}_{3}$ ) $\delta / \mathrm{ppm}: 1.59$ (bs, $1 \mathrm{H}, \mathrm{NH}), 2.91(\mathrm{~m}, 4 \mathrm{H}$, piperzinyl $\mathrm{H}), 2.98(\mathrm{~m}, 4 \mathrm{H}$, piperzinyl $\mathrm{H}), 7.51-7.60(\mathrm{~m}, 3 \mathrm{H}, \mathrm{Ar}-\mathrm{H}), 7.70-7.75(\mathrm{~m}, 2 \mathrm{H}$, $\mathrm{Ar}-\mathrm{H}) ;{ }^{13} \mathrm{C}$ NMR $\left(75 \mathrm{MHz}, \mathrm{CDCl}_{3}\right) \delta / \mathrm{ppm}: 45.1,50.5,115.6$, 126.5, 128.2; ESI-MS m/z: $226(\mathrm{M})^{+}$.

\section{General procedure for the synthesis of $\mathbf{3} a-j$ and $\mathbf{4 a}-\boldsymbol{j}$}

To a mixture of hippuric acid 1 (5 mmol), 4-substitutedphenyl-sulfonylpiperazine $(6 \mathrm{mmol})$, and HOBt hydrate $(6 \mathrm{mmol})$ in DMF $(5 \mathrm{~mL})$ were added to EDCl $(6 \mathrm{mmol})$ and the mixture was stirred at room temperature for 4- $6 \mathrm{~h}$. After the completion of reaction(confirmed by TLC), the reaction mixture was poured into ice cold water, the precipitate obtained was filtered and washed with water to afford the desired product. The pure compounds ( $\mathbf{3} \mathbf{a}-\mathbf{j}$ and 4a-j) were isolated by column chromatography using $4: 6$ of Ethyl acetate: Hexane as eluent.

$\mathrm{N}$-(2-oxo-2-(4-(phenylsulfonyl)piperazin-1-yl)ethyl)benzamide (3a)

White solid. Yield: $85 \%$; mp: $154-156{ }^{\circ} \mathrm{C}$; IR (KBr) $\tilde{v} / \mathrm{cm}^{-1}$ : $1172,1653,2859,2935,2982,3067,3423$; ${ }^{1} \mathrm{H}$ NMR (300 $\left.\mathrm{MHz}, \mathrm{CDCl}_{3}\right) \delta /$ ppm: 3.02-3.14 (m, 4H, piperzinyl $\left.\mathrm{H}\right), 3.50-$ $3.62(\mathrm{~m}, 2 \mathrm{H}$, piperzinyl $\mathrm{H}), 3.71-3.79(\mathrm{~m}, 2 \mathrm{H}$, piperzinyl $\mathrm{H})$, $4.20\left(\mathrm{~d}, 2 \mathrm{H}, \mathrm{J}=3.8 \mathrm{~Hz}, \mathrm{COCH}_{2} \mathrm{NH}\right), 7.03-7.21(\mathrm{~m}, 3 \mathrm{H}, \mathrm{Ar}-\mathrm{H})$, 7.57-7.63 (m, 3H, Ar-H), 7.72-7.85 (m, 4H, Ar-H); ${ }^{13} \mathrm{C}$ NMR 
(75 MHz, $\mathrm{CDCl}_{3}$ ) $\delta / \mathrm{ppm:} \mathrm{40.8,} \mathrm{41.1,} \mathrm{43.6,} \mathrm{45.3,} \mathrm{45.5,} \mathrm{116.1,}$ 125.7, 126.5, 128.1, 129.3, 130.9, 132.5, 166.6, 167.5; ESIMS $m / z: 388(\mathrm{M}+1)^{+}, 410(\mathrm{M}+23)^{+}$. Anal. Calcd for $\mathrm{C}_{19} \mathrm{H}_{21} \mathrm{~N}_{3} \mathrm{O}_{4} \mathrm{~S}: \mathrm{C}, 58.90 ; \mathrm{H}, 5.47 ; \mathrm{N}, 10.85$. Found: $\mathrm{C}, 58.84 ; \mathrm{H}$, 5.43; N, 10.76 .

N-(2-oxo-2-(4-tosylpiperazin-1-yl)ethyl)benzamide (3b) White solid. Yield: $81 \%$; $\mathrm{mp}: 145-147^{\circ} \mathrm{C}$; IR (KBr) $\tilde{v} / \mathrm{cm}^{-1}$ : 1159, 1669, 1645, 2854, 2924, 3392; ${ }^{1 \mathrm{H}}$ NMR $(300 \mathrm{MHz}$, $\mathrm{CDCl}_{3}$ ) $\delta / \mathrm{ppm}: 2.43\left(\mathrm{~s}, 3 \mathrm{H}, \mathrm{Ph}-\mathrm{CH}_{3}\right), 2.97-3.11(\mathrm{~m}, 4 \mathrm{H}$, piperzinyl $\mathrm{H}), 3.55-3.62(\mathrm{~m}, 2 \mathrm{H}$, piperzinyl $\mathrm{H}), 3.74-3.83(\mathrm{~m}$, $2 \mathrm{H}$, piperzinyl $\mathrm{H}), 4.18\left(\mathrm{~d}, 2 \mathrm{H}, J=3.9 \mathrm{~Hz}, \mathrm{COCH}_{2} \mathrm{NH}\right), 7.16$ (bs, $1 \mathrm{H}, \mathrm{NH}), 7.30-7.37(\mathrm{~m}, 2 \mathrm{H}, \mathrm{Ar}-\mathrm{H}), 7.39-7.48(\mathrm{~m}, 2 \mathrm{H}$, $\mathrm{Ar}-\mathrm{H}), 7.50(\mathrm{~m}, 1 \mathrm{H}, \mathrm{Ar}-\mathrm{H}), 7.58-7.67(\mathrm{~m}, 2 \mathrm{H}, \mathrm{Ar}-\mathrm{H}), 7.75-$ 7.85 (m, 2H, Ar-H); ${ }^{13} \mathrm{C} \mathrm{NMR} \mathrm{(75} \mathrm{MHz,} \mathrm{CDCl}_{3}$ ) $\delta / \mathrm{ppm}: 21.5$, 41.0, 41.5, 43.8, 45.6, 45.8, 115.9, 126.9, 127.6, 128.5, 131.7, 132.8, 133.6, 166.5, 167.1; ESI-MS m/z: $402(\mathrm{M}+1)^{+}$, $424(\mathrm{M}+23)^{+}$. Anal. Calcd for $\mathrm{C}_{20} \mathrm{H}_{23} \mathrm{~N}_{3} \mathrm{O}_{4} \mathrm{~S}: \mathrm{C}, 59.83 ; \mathrm{H}, 5.78$; $\mathrm{N}, 10.47$. Found: $\mathrm{C}, 59.76 ; \mathrm{H}, 5.65 ; \mathrm{N}, 10.32$.

\section{$\mathrm{N}-(2-(4-((4-($ tert-butyl)phenyl)sulfonyl)piperazin-1-yl)-2-} oxoethyl)benzamide (3c)

White solid. Yield: $88 \%$; $\mathrm{mp}$ : $134-136{ }^{\circ} \mathrm{C}$; IR $(\mathrm{KBr}) \tilde{\mathrm{v}} / \mathrm{cm}^{-1}$ : 1166, 1650, 1674, 2925, 2961, 3099, 3304; ${ }^{1} \mathrm{H}$ NMR (300 $\left.\mathrm{MHz}, \mathrm{CDCl}_{3}\right) \delta / \mathrm{ppm}: 1.35\left(\mathrm{~s}, 9 \mathrm{H}, 3 \mathrm{xCH}_{3}\right), 3.02-3.12(\mathrm{~m}, 4 \mathrm{H}$ piperzinyl $\mathrm{H}), 3.58(\mathrm{t}, 2 \mathrm{H}, J=5.0 \mathrm{~Hz}$, piperzinyl $\mathrm{H}), 3.78(\mathrm{t}$, $2 \mathrm{H}, J=5.0 \mathrm{~Hz}$, piperzinyl $\mathrm{H}), 4.20(\mathrm{~d}, 2 \mathrm{H}, J=3.4 \mathrm{~Hz}$, $\left.\mathrm{COCH}_{2} \mathrm{NH}\right), 7.39-7.59(\mathrm{~m}, 3 \mathrm{H}, \mathrm{Ar}-\mathrm{H}), 7.64-7.70(\mathrm{~m}, 2 \mathrm{H}, \mathrm{Ar}-$ H), 7.76-7.82 (m, 2H, Ar-H); ${ }^{13} \mathrm{C}$ NMR $\left(75 \mathrm{MHz}, \mathrm{CDCl}_{3}\right)$ S/ppm: 31.0, 34.1, 41.4, 41.5, 43.9, 45.7, 45.9, 126.3, 127.0, 127.6, 128.5, 131.7, 133.6, 151.1, 166.5, 167.2; ESI-MS m/z: $444(\mathrm{M}+1)^{+}, 466(\mathrm{M}+23)^{+}$. Anal. Calcd for $\mathrm{C}_{23} \mathrm{H}_{29} \mathrm{~N}_{3} \mathrm{O}_{4} \mathrm{~S}: \mathrm{C}$, 62.28; H, 6.59; N, 9.48. Found: C, 62.12; H, 6.38; N, 9.32.

$\mathrm{N}$-(2-(4-((4-methoxyphenyl)sulfonyl)piperazin-1-yl)-2oxoethyl)benzamide (3d)

White solid. Yield: $80 \%$. mp: $126-128{ }^{\circ} \mathrm{C}$; IR (KBr) $\tilde{v} / \mathrm{cm}^{-1}$ : 1161, 1638, 2854, 2924, 3097, 3299; ${ }^{1} \mathrm{H}$ NMR (300 MHz, $\mathrm{CDCl}_{3}$ ) $\delta /$ ppm: 2.99-3.09 (m, 4H, piperzinyl $\left.\mathrm{H}\right), 3.58(\mathrm{t}, 2 \mathrm{H}$, $J=5.2 \mathrm{~Hz}$, piperzinyl $\mathrm{H}), 3.78(\mathrm{t}, 2 \mathrm{H}, J=5.2 \mathrm{~Hz}$, piperzinyl $\mathrm{H})$, $3.92\left(\mathrm{~s}, 3 \mathrm{H}, \mathrm{Ph}-\mathrm{OCH}_{3}\right), 4.20\left(\mathrm{~d}, 2 \mathrm{H}, J=3.8 \mathrm{~Hz}, \mathrm{COCH}_{2} \mathrm{NH}\right)$, 6.99-7.05 (m, 2H, Ar-H), 7.14-7.21(m, 1H, Ar-H), 7.40$7.55(\mathrm{~m}, 3 \mathrm{H}, \mathrm{Ar}-\mathrm{H}), 7.66-7.72(\mathrm{~m}, 2 \mathrm{H}, \mathrm{Ar}-\mathrm{H}), 7.77-7.83(\mathrm{~m}$, $2 \mathrm{H}, \mathrm{Ar}-\mathrm{H}) ;{ }^{13} \mathrm{C}$ NMR (125 MHz, $\mathrm{CDCl}_{3}$ ) $\delta / \mathrm{ppm}: 41.1,42.0$, 44.3, 46.4, 46.1, 55.9, 115.9, 116.2, 129.3, 129.6, 130.5, 135.2, 167.1, 167.3; ESI-MS m/z: $418(\mathrm{M}+1)^{+}, 440(\mathrm{M}+23)^{+}$. Anal. Calcd for $\mathrm{C}_{20} \mathrm{H}_{23} \mathrm{~N}_{3} \mathrm{O}_{5} \mathrm{~S}: \mathrm{C}, 57.54 ; \mathrm{H}, 5.56 ; \mathrm{N}, 10.07$. Found: C, 57.39; H, 5.42; N, 10.00 .

\section{$\mathrm{N}$-(2-(4-((4-fluorophenyl)sulfonyl)piperazin-1-yl)-2-}

oxoethyl)benzamide (3e)

White solid. Yield: $78 \%$. mp: $138-140{ }^{\circ} \mathrm{C}$; IR (KBr) $\tilde{v} / \mathrm{cm}^{-1}$ : 1165, 1658, 2864, 2921, 3068, 3412; ${ }^{1} \mathrm{H}$ NMR (400 MHz, $\mathrm{CDCl}_{3}$ ) $\delta /$ ppm: 3.01-3.12 (m, 4H, piperzinyl $\left.\mathrm{H}\right), 3.60(\mathrm{t}, 2 \mathrm{H}$, $J=5.2 \mathrm{~Hz}$, piperzinyl $\mathrm{H}), 3.79(\mathrm{t}, 2 \mathrm{H}, J=5.2 \mathrm{~Hz}$, piperzinyl $\mathrm{H})$, $4.21\left(\mathrm{~d}, 2 \mathrm{H}, J=3.7 \mathrm{~Hz}, \mathrm{COCH}_{2} \mathrm{NH}\right), 7.17$ (bs, $\left.1 \mathrm{H}, \mathrm{NH}\right), 7.21-$ $7.29(\mathrm{~m}, 2 \mathrm{H}, \mathrm{Ar}-\mathrm{H}), 7.40-7.54(\mathrm{~m}, 3 \mathrm{H}, \mathrm{Ar}-\mathrm{H}), 7.74-7.83(\mathrm{~m}$, $4 \mathrm{H}, \mathrm{Ar}-\mathrm{H}) ;{ }^{13} \mathrm{C}$ NMR $\left(75 \mathrm{MHz}, \mathrm{CDCl}_{3}\right) \delta / \mathrm{ppm}: 41.3,41.5$, 43.8, 45.6, 45.8, 116.5, 116.7, 126.9, 128.5, 130.3, 131.7, 133.5, 163.7, 166.5, 167.1; ESI-MS m/z: $406(\mathrm{M}+1)^{+}, 428$ $(\mathrm{M}+23)^{+}$. Anal. Calcd for $\mathrm{C}_{19} \mathrm{H}_{20} \mathrm{FN}_{3} \mathrm{O}_{4} \mathrm{~S}: \mathrm{C}, 56.28 ; \mathrm{H}, 4.98 ; \mathrm{N}$, 10.37. Found: $C, 56.12 ; \mathrm{H}, 4.26$; N, 10.25 .

$\mathrm{N}$-(2-oxo-2-(4-((4-(trifluoromethyl)phenyl)sulfonyl)piperazin-1-yl)ethyl)benzamide(3f)

White solid. Yield: $75 \%$; $\mathrm{mp}$ : $132-134{ }^{\circ} \mathrm{C}$; IR (KBr) $\tilde{v} / \mathrm{cm}^{-1}$ : $1173,1213,1651,2857,2924,3403 ;^{1} \mathrm{H}$ NMR $(400 \mathrm{MHz}$, $\left.\mathrm{CDCl}_{3}\right)$ 8/ppm: 3.02-3.16 (m, 4H, piperzinyl $\left.\mathrm{H}\right), 3.54-3.64$ ( $\mathrm{m}, 2 \mathrm{H}$, piperzinyl $\mathrm{H}), 3.73-3.82(\mathrm{~m}, 2 \mathrm{H}$, piperzinyl $\mathrm{H}), 4.20$ (d, $\left.2 \mathrm{H}, J=3.9 \mathrm{~Hz}, \mathrm{COCH}_{2} \mathrm{NH}\right), 7.16$ (bs, $\left.1 \mathrm{H}, \mathrm{NH}\right), 7.33-7.52$ (m, 5H, Ar-H), 7.74-7.45 (m, 4H, Ar-H); ${ }^{13} \mathrm{C} \mathrm{NMR} \mathrm{(75} \mathrm{MHz,}$ $\mathrm{CDCl}_{3}$ ) $\delta /$ ppm: 41.3, 41.5, 43.9, 45.6, 45.7, 116.2, 124.4, $126.5,126.9,128.1,128.5,131.8,133.5,138.8,144.1$, 166.6, 167.1; ESI-MS m/z: $456(\mathrm{M}+1)^{+}, 478(\mathrm{M}+23)^{+}$. Anal. Calcd for $\mathrm{C}_{20} \mathrm{H}_{20} \mathrm{~F}_{3} \mathrm{~N}_{3} \mathrm{O}_{4} \mathrm{~S}$ : C, 52.73; $\mathrm{H}, 4.43 ; \mathrm{N}, 9.23$. Found: C, 52.52; H, 4.30; N, 9.03 .

$\mathrm{N}$-(2-oxo-2-(4-((4-(trifluoromethoxy)phenyl)sulfonyl)piperazin-1-yl)ethyl)benzamide(3g)

White solid. Yield: $87 \%$; $\mathrm{mp}$ : $140-142{ }^{\circ} \mathrm{C}$; IR (KBr) $\tilde{v} / \mathrm{cm}^{-1}$ : $1123,1166,1647,2845,2932,3411 ;{ }^{1} \mathrm{H}$ NMR $(300 \mathrm{MHz}$, $\left.\mathrm{CDCl}_{3}\right)$ 8/ppm: 3.03-3.18 (m, 4H, piperzinyl $\left.\mathrm{H}\right), 3.56-3.66$ ( $\mathrm{m}, 2 \mathrm{H}$, piperzinyl $\mathrm{H}), 3.76-3.84(\mathrm{~m}, 2 \mathrm{H}$, piperzinyl $\mathrm{H}), 4.21$ (d, $\left.2 \mathrm{H}, J=4.0 \mathrm{~Hz}, \mathrm{COCH}_{2} \mathrm{NH}\right), 7.13-7.21(\mathrm{~m}, 1 \mathrm{H}, \mathrm{Ar}-\mathrm{H}), 7.39-$ 7.55 (m, 3H, Ar-H), 7.76-7.94 (m, 6H, Ar-H); ${ }^{13} \mathrm{C}$ NMR (75 $\left.\mathrm{MHz}, \mathrm{CDCl}_{3}\right) \delta / \mathrm{ppm}: 41.5,41.8,43.9,45.6,45.8,115.2$, 126.3, 126.2, 128.2, 128.6, 132.5, 139.5, 165.3, 167.2; ESIMS $m / z: 472(\mathrm{M}+1)^{+}, 494(\mathrm{M}+23)^{+}$. Anal. Calcd for $\mathrm{C}_{20} \mathrm{H}_{20} \mathrm{~F}_{3} \mathrm{~N}_{3} \mathrm{O}_{5} \mathrm{~S}: \mathrm{C}, 50.94 ; \mathrm{H}, 4.28 ; \mathrm{N}, 8.92$. Found: $\mathrm{C}, 50.81$; $\mathrm{H}, 4.06 ; \mathrm{N}, 8.69$.

\section{$N-(2-(4-((4-n i t r o p h e n y l) s u l f o n y l) p i p e r a z i n-1-y l)-2-o x o-$ ethyl)benzamide(3h)}

Pale yellow solid. Yield: $70 \%$; mp: $112-114{ }^{\circ} \mathrm{C}$; IR (KBr) $\tilde{v} / \mathrm{cm}^{-1}: 3414,3112,2933,2857,1672,1346,1160 ;{ }^{1} \mathrm{H}$ NMR (400 MHz, $\left.\mathrm{CDCl}_{3}\right) \delta / p p m: ~ 3.07-3.18(\mathrm{~m}, 4 \mathrm{H}$, piperzinyl $\mathrm{H})$, $3.62(\mathrm{t}, 2 \mathrm{H}, J=4.7 \mathrm{~Hz}$, piperzinyl $\mathrm{H}), 3.80(\mathrm{t}, 2 \mathrm{H}, J=4.7 \mathrm{~Hz}$, piperzinyl $\mathrm{H}), 4.21\left(\mathrm{~d}, 2 \mathrm{H}, J=4.3 \mathrm{~Hz}, \mathrm{COCH}_{2} \mathrm{NH}\right), 7.12-7.19$ (m, $1 \mathrm{H}, \mathrm{Ar}-\mathrm{H}), 7.39-7.55(\mathrm{~m}, 3 \mathrm{H}, \mathrm{Ar}-\mathrm{H}), 7.76-7.83(\mathrm{~m}, 2 \mathrm{H}$, Ar-H), 7.93-8.01 (m, 2H, Ar-H), 8.38-8.45 (m, 2H, Ar-H); ${ }^{13} \mathrm{C} \mathrm{NMR}\left(75 \mathrm{MHz}, \mathrm{CDCl}_{3}\right.$ ) $\delta / \mathrm{ppm}: 41.7,41.9,43.9,45.6$, 45.7, 116.2, 126.4, 128.1, 128.5, 131.8, 138.5, 149.8, 165.8, 166.6; ESI-MS m/z: $433(\mathrm{M}+1)^{+}, 455(\mathrm{M}+23)^{+}$. Anal. Calcd for $\mathrm{C}_{19} \mathrm{H}_{20} \mathrm{~N}_{4} \mathrm{O}_{6} \mathrm{~S}: \mathrm{C}, 52.76 ; \mathrm{H}, 4.66 ; \mathrm{N}, 12.96$. Found: $\mathrm{C}, 52.55 ; \mathrm{H}$, $4.52 ; \mathrm{N}, 12.74$.

$\mathrm{N}$-(2-oxo-2-(4-(thiophen-2-ylsulfonyl)piperazin-1-yl)ethyl)benzamide (3i)

White solid. Yield: $76 \%$; $\mathrm{mp}: 125-126^{\circ} \mathrm{C}$; IR $(\mathrm{KBr}) \tilde{\mathrm{v}} / \mathrm{cm}^{-1}$ : 3379, 2921, 2858, 1657, 1149; ${ }^{1} \mathrm{H}$ NMR (300 MHz, CDCl $)$ 


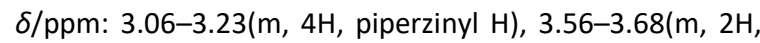
piperzinyl $\mathrm{H}), 3.76-3.87(\mathrm{~m}, 2 \mathrm{H}$, piperzinyl $\mathrm{H}), 4.23(\mathrm{~d}, 2 \mathrm{H}, \mathrm{J}$ $\left.=3.8 \mathrm{~Hz}, \mathrm{COCH}_{2} \mathrm{NH}\right), 7.12-7.22(\mathrm{~m}, 2 \mathrm{H}, \mathrm{Ar}-\mathrm{H}), 7.40-7.48(\mathrm{~m}$, $2 \mathrm{H}, \mathrm{Ar}-\mathrm{H}), 7.48-7.59(\mathrm{~m}, 3 \mathrm{H}, \mathrm{Ar}-\mathrm{H}), 7.63-7.70(\mathrm{~m}, 1 \mathrm{H}, \mathrm{Ar}-$ H), 7.76-7.87 (m, 2H, Ar-H); ${ }^{13} \mathrm{C}$ NMR $\left(75 \mathrm{MHz}, \mathrm{CDCl}_{3}\right)$ $\delta /$ ppm: 41.2, 41.9, 43.2, 45.2, 45.7, 116.5, 126.5, 126.8, 128.5, 129.1, 134.0, 166.8, 167.6; ESI-MS m/z: $395(\mathrm{M}+1)^{+}$, $417(\mathrm{M}+23)^{+}$. Anal. Calcd for $\mathrm{C}_{17} \mathrm{H}_{19} \mathrm{~N}_{3} \mathrm{O}_{4} \mathrm{~S}_{2}: \mathrm{C}, 51.90 ; \mathrm{H}, 4.87$; $\mathrm{N}, 10.69$. Found: $\mathrm{C}, 51.66 ; \mathrm{H}, 4.72 ; \mathrm{N}, 10.54$.

$\mathrm{N}$-(2-(4-((4-bromophenyl)sulfonyl)piperazin-1-yl)-2-oxoethyl)benzamide (3j)

White solid. Yield: $81 \%$; $\mathrm{mp}: 154-156^{\circ} \mathrm{C}$; IR $(\mathrm{KBr}) \tilde{\mathrm{v}} / \mathrm{cm}^{-1}$ : $1156,1632,2850,2914,3075,3412$; ${ }^{1} \mathrm{H}$ NMR $(400 \mathrm{MHz}$, $\left.\mathrm{CDCl}_{3}\right) \delta /$ ppm: 3.00-3.11 (m, 4H, piperzinyl $\left.\mathrm{H}\right), 3.42-3.49$ (m, $2 \mathrm{H}$, piperzinyl $\mathrm{H}), 3.62-3.67(\mathrm{~m}, 2 \mathrm{H}$, piperzinyl $\mathrm{H}), 4.20$ (d, $\left.2 \mathrm{H}, J=4.2 \mathrm{~Hz}, \mathrm{COCH}_{2} \mathrm{NH}\right), 7.14-7.20(\mathrm{~m}, 1 \mathrm{H}, \mathrm{Ar}-\mathrm{H}), 7.21-$ $7.29(\mathrm{~m}, 2 \mathrm{H}, \mathrm{Ar}-\mathrm{H}), 7.40-7.54(\mathrm{~m}, 3 \mathrm{H}, \mathrm{Ar}-\mathrm{H}), 7.74-7.83(\mathrm{~m}$, $4 \mathrm{H}, \mathrm{Ar}-\mathrm{H}) ;{ }^{13} \mathrm{C}$ NMR $\left(75 \mathrm{MHz}, \mathrm{CDCl}_{3}\right) \delta / \mathrm{ppm}: 41.1,41.5$, 44.0, 45.2, 45.5, 116.4, 126.7, 128.1, 128.5, 129.4, 130.2, 133.6, 166.5, 167.1; ESI-MS m/z: $467(\mathrm{M}+1)^{+}$. Anal. Calcd for $\mathrm{C}_{19} \mathrm{H}_{20} \mathrm{BrN}_{3} \mathrm{O}_{4} \mathrm{~S}: \mathrm{C}, 48.92 ; \mathrm{H}, 4.33 ; \mathrm{N}, 9.01$. Found: $\mathrm{C}$, 48.72; $\mathrm{H}, 4.21 ; \mathrm{N}, 8.89$.

\section{4-fluoro-N-(2-oxo-2-(4-(phenylsulfonyl)piperazin-1-yl)- ethyl)benzamide (4a) \\ White solid. Yield: $79 \%$; mp: $154-156^{\circ} \mathrm{C} ; \mathrm{IR}(\mathrm{KBr}) \tilde{\mathrm{v}} / \mathrm{cm}^{-1}: 1164$, 1649, 2855, 2922, 2998, 3067, 3413; ${ }^{1} \mathrm{H}$ NMR (300 MHz, $\left.\mathrm{CDCl}_{3}\right) \delta / p p m: 3.01-3.16(\mathrm{~m}, 4 \mathrm{H}$, piperzinyl $\mathrm{H}), 3.54-3.65$ (m, $2 \mathrm{H}$, piperzinyl $\mathrm{H}), 3.73-3.83(\mathrm{~m}, 2 \mathrm{H}$, piperzinyl $\mathrm{H}), 4.17(\mathrm{~d}, 2 \mathrm{H}$, $\left.J=4.5 \mathrm{~Hz}, \mathrm{COCH}_{2} \mathrm{NH}\right), 7.07-7.19(\mathrm{~m}, 3 \mathrm{H}, \mathrm{Ar}-\mathrm{H}), 7.53-7.67(\mathrm{~m}$, $3 \mathrm{H}, \mathrm{Ar}-\mathrm{H}), 7.73-7.89(\mathrm{~m}, 4 \mathrm{H}, \mathrm{Ar}-\mathrm{H}) ;{ }^{13} \mathrm{C} \mathrm{NMR}\left(75 \mathrm{MHz}, \mathrm{CDCl}_{3}\right)$ ס/ppm: 41.2, 41.5, 43.4, 45.6, 45.9, 116.8, 125.3, 127.6, 128.2, 130.6, 130.9, 132.5, 163.5, 165.9, 167.2; ESI-MS m/z: 406 $(\mathrm{M}+1)^{+}, 428(\mathrm{M}+23)^{+}$. Anal. Calcd for $\mathrm{C}_{19} \mathrm{H}_{20} \mathrm{FN}_{3} \mathrm{O}_{4} \mathrm{~S}: \mathrm{C}, 56.28$; $H, 4.98 ; N, 10.37$. Found: C, 56.12; H, 4.82; N, 10.19 .}

\section{4-fluoro-N-(2-oxo-2-(4-tosylpiperazin-1-yl)ethyl)benz-} amide(4b)

White solid. Yield:77 \%; mp: $127-129^{\circ} \mathrm{C}$; IR (KBr) $\tilde{v} / \mathrm{cm}^{-1}$ : 1159, 1669, 1645, 2854, 2924, 3392; ${ }^{1} \mathrm{H}$ NMR $(400 \mathrm{MHz}$, $\mathrm{CDCl}_{3}$ ) $\delta / \mathrm{ppm}: 2.37\left(\mathrm{~s}, 3 \mathrm{H}, \mathrm{Ph}-\mathrm{CH}_{3}\right), 2.90-3.04(\mathrm{~m}, 4 \mathrm{H}$, piperzinyl $\mathrm{H}), 3.49(\mathrm{~m}, 2 \mathrm{H}$, piperzinyl $\mathrm{H}), 3.70(\mathrm{~m}, 2 \mathrm{H}$, piperzinyl $\mathrm{H}$ ), $4.10\left(\mathrm{~d}, 2 \mathrm{H}, \mathrm{J}=2.7 \mathrm{~Hz}, \mathrm{COCH}_{2} \mathrm{NH}\right), 6.99-7.08(\mathrm{~m}$, $2 \mathrm{H}, \mathrm{Ar}-\mathrm{H}), 7.28-7.31(\mathrm{~m}, 2 \mathrm{H}, \mathrm{Ar}-\mathrm{H}), 7.53-7.60(\mathrm{~m}, 2 \mathrm{H}, \mathrm{Ar}-\mathrm{H})$, 7.70-7.78 (m, 3H, Ar-H); ${ }^{13} \mathrm{C}$ NMR (75 MHz, $\left.\mathrm{CDCl}_{3}\right) \delta / \mathrm{ppm}$ : $21.3,41.5,41.7,43.2,45.1,45.5,115.9,126.6,127.6,128.3$, 128.9, 130.5, 135.4, 163.8, 166.9, 167.5; ESI-MS m/z: 420 $(\mathrm{M}+1)^{+}, 342(\mathrm{M}+23)^{+}$. Anal. Calcd for $\mathrm{C}_{20} \mathrm{H}_{22} \mathrm{FN}_{3} \mathrm{O}_{4} \mathrm{~S}: \mathrm{C}, 57.26$; $H, 5.29 ; N, 10.02$. Found: C, 57.08; H, 5.15; N, 9.93.

N-(2-(4-((4-(tert-butyl)phenyl)sulfonyl)piperazin-1-yl)-2oxoethyl)-4-fluorobenzamide(4c)

White solid. Yield: $87 \%$; $\mathrm{mp}: 114-116{ }^{\circ} \mathrm{C} ; \mathrm{IR}(\mathrm{KBr}) \tilde{v} / \mathrm{cm}^{-1}$ : 1166, 1650, 1674, 2925, 2961, 3099, 3304; ${ }^{1} \mathrm{H}$ NMR (300
$\left.\mathrm{MHz}, \mathrm{CDCl}_{3}\right) \delta / \mathrm{ppm}: 1.35\left(\mathrm{~s}, 9 \mathrm{H}, 3 \times \mathrm{CH}_{3}\right), 3.03-3.12(\mathrm{~m}, 4 \mathrm{H}$, piperzinyl $\mathrm{H}), 3.57(\mathrm{~m}, 2 \mathrm{H}$, piperzinyl $\mathrm{H}), 3.77(\mathrm{~m}, 2 \mathrm{H}$, piperzinyl $\mathrm{H}), 4.18\left(\mathrm{~d}, 2 \mathrm{H}, J=3.3 \mathrm{~Hz}, \mathrm{COCH}_{2} \mathrm{NH}\right), 7.07-7.13$ (m, 2H, Ar-H), 7.53-7.58 (m, 2H, Ar-H), 7.64-7.69 (m, 2H, $\mathrm{Ar}-\mathrm{H})$, 7.78-7.83 (m, 3H, Ar-H); ${ }^{13} \mathrm{C}$ NMR $\left(75 \mathrm{MHz}, \mathrm{CDCl}_{3}\right)$ $\delta / p p m: 31.0,35.3,41.5,42.0,43.2,45.5,45.8,117.0,125.2$, 126.6, 127.1, 128.3, 131.5, 135.1, 148.2, 162.3, 166.9, 167.7; ESI-MS m/z: $462(\mathrm{M}+1)^{+}, 484(\mathrm{M}+23)^{+}$. Anal. Calcd for $\mathrm{C}_{23} \mathrm{H}_{29} \mathrm{FN}_{3} \mathrm{O}_{4} \mathrm{~S}: \mathrm{C}, 59.72 ; \mathrm{H}, 6.32 ; \mathrm{N}, 9.09$. Found: $\mathrm{C}, 59.65 ; \mathrm{H}$, $6.21 ; \mathrm{N}, 9.00$.

4-fluoro-N-(2-(4-((4-methoxyphenyl)sulfonyl)piperazin-1yl)-2-oxoethyl)benzamide (4d)

White solid. Yield: $76.5 \%$; mp: $123-125{ }^{\circ} \mathrm{C}$; IR (KBr) $\tilde{v} / \mathrm{cm}^{-1}: 1155,1623,1662,2854,2924,3097,3299 ;{ }^{1} \mathrm{H}$ NMR $\left(300 \mathrm{MHz}, \mathrm{CDCl}_{3}\right) \delta / \mathrm{ppm}: 2.97-3.12(\mathrm{~m}, 4 \mathrm{H}$, piperzinyl $\mathrm{H}), 3.52-3.63(\mathrm{~m}, 2 \mathrm{H}$, piperzinyl $\mathrm{H}), 3.72-3.83$ $(\mathrm{m}, 2 \mathrm{H}$, piperzinyl $\mathrm{H}), 3.88\left(\mathrm{~s}, 3 \mathrm{H}, \mathrm{Ph}-\mathrm{OCH}_{3}\right), 4.17(\mathrm{~d}, 2 \mathrm{H}, \mathrm{J}$ $\left.=4.5 \mathrm{~Hz}, \mathrm{COCH}_{2} \mathrm{NH}\right), 6.97-7.19(\mathrm{~m}, 5 \mathrm{H}, \mathrm{Ar}-\mathrm{H}), 7.65-7.73$ $(\mathrm{m}, 2 \mathrm{H}, \mathrm{Ar}-\mathrm{H}), 7.77-7.86(\mathrm{~m}, 1 \mathrm{H}, \mathrm{Ar}-\mathrm{H}) ;{ }^{13} \mathrm{C}$ NMR (125 $\left.\mathrm{MHz} \mathrm{CDCl}_{3}\right) \delta / \mathrm{ppm}: 41.4,41.6,43.9,45.7,45.9,55.7$, $115.5,115.8,129.3,129.4,129.9,134.2,163.4,166.1$, 166.5; ESI-MS m/z: $458(\mathrm{M}+1)^{+}, 480(\mathrm{M}+23)^{+}$. Anal. Calcd for $\mathrm{C}_{20} \mathrm{H}_{22} \mathrm{FN}_{3} \mathrm{O}_{5} \mathrm{~S}: \mathrm{C}, 55.16 ; \mathrm{H}, 5.10 ; \mathrm{N}, 9.65$. Found: $\mathrm{C}$, $55.02 ; \mathrm{H}, 5.02 ; \mathrm{N}, 9.43$.

4-fluoro-N-(2-(4-((4-fluorophenyl)sulfonyl)piperazin-1-yl)2-oxoethyl)benzamide (4e)

White solid. Yield: $79 \%$; $\mathrm{mp}$ : $161-163^{\circ} \mathrm{C}$; IR $(\mathrm{KBr}) \tilde{\mathrm{v}} / \mathrm{cm}^{-1}$ : 1162, 1638, 1657, 2864, 2921, 3068, 3412; ${ }^{1} \mathrm{H}$ NMR (300 $\left.\mathrm{MHz}, \mathrm{CDCl}_{3}\right) \delta / \mathrm{ppm}$ : 3.01-3.13 (m, 4H, piperzinyl $\mathrm{H}$ ), 3.55-3.62 (m, 2H, piperzinyl $\mathrm{H}), 3.74-3.83(\mathrm{~m}, 2 \mathrm{H}$, piperzinyl $\mathrm{H}), 4.18\left(\mathrm{~d}, 2 \mathrm{H}, J=3.9 \mathrm{~Hz}, \mathrm{COCH}_{2} \mathrm{NH}\right), 7.06-$ $7.15(\mathrm{~m}, 3 \mathrm{H}, \mathrm{Ar}-\mathrm{H}), 7.23-7.29(\mathrm{~m}, 2 \mathrm{H}, \mathrm{Ar}-\mathrm{H}), 7.75-7.85$ (m, 4H, $\mathrm{Ar}-\mathrm{H}) ;{ }^{13} \mathrm{C}$ NMR (75 MHz, $\mathrm{CDCl}_{3}$ ) $\delta / \mathrm{ppm}: 41.4$, 41.6, 43.9, 45.6, 45.8, 115.5, 115.8, 116.5, 116.8, 129.3, 129.4, 130.3, 130.4, 134.5, 163.2, 163.8, 166.1, 166.5; ESI-MS $m / z$ : $424(\mathrm{M}+1)^{+}, 446(\mathrm{M}+23)^{+}$. Anal. Calcd for $\mathrm{C}_{19} \mathrm{H}_{19} \mathrm{~F}_{2} \mathrm{~N}_{3} \mathrm{O}_{4} \mathrm{~S}: \mathrm{C}, 53.89 ; \mathrm{H}, 4.53 ; \mathrm{N}, 9.93$. Found: C, 53.62; $\mathrm{H}, 4.36 ; \mathrm{N}, 9.71$.

4-fluoro-N-(2-oxo-2-(4-((4-(trifluoromethyl)phenyl)sulfonyl)piperazin-1-yl)ethyl)benzamide (4f)

White solid. Yield: $82 \%$; $\mathrm{mp}: 155-157^{\circ} \mathrm{C}$; IR (KBr) $\tilde{v} / \mathrm{cm}^{-1}$ : $1161,1213,1629,1653,2857,2924,3403$; ${ }^{1} \mathrm{H}$ NMR (300 $\left.\mathrm{MHz}, \mathrm{CDCl}_{3}\right) \delta /$ ppm: 3.04-3.15 (m, 4H, piperzinyl $\left.\mathrm{H}\right), 3.56-$ $3.64(\mathrm{~m}, 2 \mathrm{H}$, piperzinyl $\mathrm{H}), 3.76-3.83(\mathrm{~m}, 2 \mathrm{H}$, piperzinyl $\mathrm{H})$, $4.20\left(\mathrm{~d}, 2 \mathrm{H}, \mathrm{J}=3.8 \mathrm{~Hz}, \mathrm{COCH}_{2} \mathrm{NH}\right), 7.06-7.16(\mathrm{~m}, 3 \mathrm{H}, \mathrm{Ar}-\mathrm{H})$, 7.35-7.42 (m, 2H, Ar-H), 7.77-7.85 (m, 3H, Ar-H); ${ }^{13} \mathrm{C} \mathrm{NMR}$ (75 MHz, $\mathrm{CDCl}_{3}$ ) $\delta / \mathrm{ppm:} \mathrm{41.5,} \mathrm{41.6,} \mathrm{43.9,} \mathrm{45.6,} \mathrm{45.8,} \mathrm{116.8,}$ $126.4,126.5,126.9,128.1,128.5,131.8,133.5,164.1$, 166.6, 167.1; ESI-MS m/z: $474(\mathrm{M}+1)^{+}, 496(\mathrm{M}+23)^{+}$. Anal. Calcd for $\mathrm{C}_{20} \mathrm{H}_{19} \mathrm{~F}_{4} \mathrm{~N}_{3} \mathrm{O}_{4} \mathrm{~S}$ : C, 50.73; $\mathrm{H}, 4.05 ; \mathrm{N}, 8.88$. Found: C, $50.55 ; \mathrm{H}, 3.95 ; \mathrm{N}, 8.62$. 
4-fluoro-N-(2-oxo-2-(4-((4-(trifluoromethoxy)phenyl)sulfonyl)piperazin-1-yl)ethyl)benzamide (4g)

White solid. Yield: $74 \%$; $\mathrm{mp}: 154-156{ }^{\circ} \mathrm{C}$; IR $(\mathrm{KBr}) \tilde{v} / \mathrm{cm}^{-1}$ : 1129, 1166, 1604, 1647, 2856, 2924, 3404; ${ }^{1 \mathrm{H}}$ NMR (400 $\left.\mathrm{MHz}, \mathrm{CDCl}_{3}\right) \delta /$ ppm: 3.07-3.16 (m, 4H, piperzinyl $\left.\mathrm{H}\right), 3.56-$ $3.64(\mathrm{~m}, 2 \mathrm{H}$, piperzinyl $\mathrm{H}), 3.75-3.83(\mathrm{~m}, 2 \mathrm{H}$, piperzinyl $\mathrm{H})$, $4.19\left(\mathrm{~d}, 2 \mathrm{H}, \mathrm{J}=3.3 \mathrm{~Hz}, \mathrm{COCH}_{2} \mathrm{NH}\right), 7.06-7.15(\mathrm{~m}, 3 \mathrm{H}, \mathrm{Ar}-\mathrm{H})$, 7.78-7.87 (m, 3H, Ar-H), 7.88-7.93 (m, 3H, Ar-H); ${ }^{13} \mathrm{C} \mathrm{NMR}$ (75 MHz, $\mathrm{CDCl}_{3}$ ) $\delta / \mathrm{ppm:} \mathrm{41.4,} \mathrm{41.6,} \mathrm{43.9,} \mathrm{45.6,} \mathrm{45.8,} \mathrm{115.5,}$ $115.8,126.5,126.5,128.1,128.2,129.5,134.0,163.6$, 165.5, 166.6; ESI-MS m/z: $490(\mathrm{M}+1)^{+}, 512(\mathrm{M}+23)^{+}$. Anal. Calcd for $\mathrm{C}_{20} \mathrm{H}_{19} \mathrm{~F}_{4} \mathrm{~N}_{3} \mathrm{O}_{5} \mathrm{~S}: \mathrm{C}, 49.07 ; \mathrm{H}, 3.92 ; \mathrm{N}, 8.59$. Found: C, 48.89; H, 3.71; N, 8.42.

\section{$\mathrm{N}$-(2-(4-((4-nitrophenyl)sulfonyl)piperazin-1-yl)-2-oxo-} ethyl)benzamide (4h)

Pale yellow white solid. Yield: $68 \%$; mp: $154-156{ }^{\circ} \mathrm{C}$; IR (KBr) $\tilde{v} / \mathrm{cm}^{-1}: 1165,1351,1677,2854,2923,3109,3402 ;{ }^{1} \mathrm{H}$

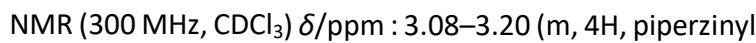
$\mathrm{H})$, 3.50-3.56 $(\mathrm{m}, 2 \mathrm{H}$, piperzinyl $\mathrm{H}), 3.67-3.74(\mathrm{~m}, 2 \mathrm{H}$, piperzinyl $\mathrm{H}), 4.21\left(\mathrm{~d}, 2 \mathrm{H}, J=3.8 \mathrm{~Hz}, \mathrm{COCH}_{2} \mathrm{NH}\right), 7.09-7.16$ (m, 1H, Ar-H), 7.39-7.55 (m, 3H, Ar-H), 7.76-7.83 (m, 2H, $\mathrm{Ar}-\mathrm{H}), 7.93-8.01(\mathrm{~m}, 1 \mathrm{H}, \mathrm{Ar}-\mathrm{H}), 8.38-8.45(\mathrm{~m}, 2 \mathrm{H}, \mathrm{Ar}-\mathrm{H})$; ${ }^{13} \mathrm{C} \mathrm{NMR}\left(75 \mathrm{MHz}, \mathrm{CDCl}_{3}\right.$ ) $\delta / \mathrm{ppm}: 42.0,42.6,43.6,45.5$, 46.2, 125.1, 126.5, 128.4, 129.1, 131.3, 133.2, 148.5, 163.6, 165.8, 167.3; ESI-MS m/z: $451(\mathrm{M}+1)^{+}, 473(\mathrm{M}+23)^{+}$. Anal. Calcd for $\mathrm{C}_{19} \mathrm{H}_{19} \mathrm{FN}_{4} \mathrm{O}_{6} \mathrm{~S}: \mathrm{C}, 50.66 ; \mathrm{H}, 4.25 ; \mathrm{N}, 12.44$. Found: C, 50.42; H, 4.10; N, 12.12 .

4-fluoro-N-(2-oxo-2-(4-(thiophen-2-ylsulfonyl)piperazin-1yl)ethyl)benzamide (4i)

White solid. Yield: $77 \%$; mp: $138-140{ }^{\circ} \mathrm{C}$; IR (KBr) $\tilde{v} / \mathrm{cm}^{-1}$ : 1157, 1627, 1645, 2854, 2924, 3390; ${ }^{1} \mathrm{H}$ NMR $(300 \mathrm{MHz}$, $\left.\mathrm{CDCl}_{3}\right) \delta / p p m: 3.01-3.23(\mathrm{~m}, 4 \mathrm{H}$, piperzinyl $\mathrm{H}), 3.53-3.70$ ( $\mathrm{m}, 2 \mathrm{H}$, piperzinyl $\mathrm{H}), 3.73-3.91(\mathrm{~m}, 2 \mathrm{H}$, piperzinyl $\mathrm{H}), 4.21$ (d, $\left.2 \mathrm{H}, J=3.6 \mathrm{~Hz}, \mathrm{COCH}_{2} \mathrm{NH}\right), 7.05-7.23(\mathrm{~m}, 4 \mathrm{H}, \mathrm{Ar}-\mathrm{H}), 7.79$ $7.86(\mathrm{~m}, 1 \mathrm{H}, \mathrm{Ar}-\mathrm{H}), 7.95-8.03(\mathrm{~m}, 2 \mathrm{H}, \mathrm{Ar}-\mathrm{H}) ;{ }^{13} \mathrm{C}$ NMR (75 $\left.\mathrm{MHz} \mathrm{CDCl}_{3}\right) \delta / \mathrm{ppm}: 42.1,42.9,43.5,45.2,45.7,123.2$, $126.3,127.8,128.1,128.5,129.4,132.9,163.5,166.8$, 168.0; ESI-MS m/z: $412(\mathrm{M}+1)^{+}, 434(\mathrm{M}+23)^{+}$. Anal. Calcd for $\mathrm{C}_{17} \mathrm{H}_{18} \mathrm{FN}_{3} \mathrm{O}_{4} \mathrm{~S}_{2}: \mathrm{C}, 49.63 ; \mathrm{H}, 4.41 ; \mathrm{N}, 10.22$. Found: $\mathrm{C}, 49.35$; $\mathrm{H}, 4.23 ; \mathrm{N}, 10.02$.

$\mathrm{N}$-(2-(4-((4-bromophenyl)sulfonyl)piperazin-1-yl)-2-oxoethyl)-4-fluorobenzamide(4j)

White solid. Yield: $81 \%$; $\mathrm{mp}: 108-110{ }^{\circ} \mathrm{C}$; IR $(\mathrm{KBr}) \tilde{v} / \mathrm{cm}^{-1}$ : $1161,1645,2855,2923,3088,3399$; ${ }^{1} \mathrm{H}$ NMR (300 MHz, $\left.\mathrm{CDCl}_{3}\right) \delta / \mathrm{ppm}$ : 3.03-3.13 (m, 4H, piperzinyl $\left.\mathrm{H}\right), 3.45-$ $3.51(\mathrm{~m}, 2 \mathrm{H}$, piperzinyl $\mathrm{H}), 3.62-3.68(\mathrm{~m}, 2 \mathrm{H}$, piperzinyl $\mathrm{H})$, $4.18\left(\mathrm{~d}, 2 \mathrm{H}, \mathrm{J}=3.9 \mathrm{~Hz}, \mathrm{COCH}_{2} \mathrm{NH}\right), 7.07-7.18(\mathrm{~m}, 3 \mathrm{H}, \mathrm{Ar}-\mathrm{H})$, 7.58-7.75 (m, 3H, Ar-H), 7.78-7.84 (m, 2H, Ar-H); ${ }^{13} \mathrm{C} \mathrm{NMR}$ $\left(75 \mathrm{MHz} \mathrm{CDCl}_{3}\right)$ ) $/ \mathrm{ppm}: 41.4,41.9,43.2,45.2,45.7,116.2$, $118.8,126.3,126.8,128.1,128.5,129.7,133.6,164.0$, 166.3, 167.5; ESI-MS m/z: $484(\mathrm{M}+1)^{+}, 506(\mathrm{M}+23)^{+}$. Anal.
Calcd for $\mathrm{C}_{19} \mathrm{H}_{19} \mathrm{BrFN}_{3} \mathrm{O}_{4} \mathrm{~S}: \mathrm{C}, 47.11 ; \mathrm{H}, 3.96 ; \mathrm{N}, 8.68$. Found: C, $46.98 ; \mathrm{H}, 3.78 ; \mathrm{N}, 8.45$.

\section{Biology}

Maintenance of the cells

The human cancer cells of various origin (HeLa: Cervical, A549: Lung, A375: Skin, MD-AMB-23: breast and T98G: brain) were procured from National Centre for Cell sciences, Pune, and maintained in DMEM containing $10 \%$ FBS with antibiotics and antimycotics at $37{ }^{\circ} \mathrm{C}, 5 \% \mathrm{CO}_{2}$ in a $\mathrm{CO}_{2}$ incubator.

\section{MTT Assay}

The cytotoxic activity of the compounds were assessed by standard MTT assay in different cancer cells after $72 \mathrm{~h}$ of drug treatment as described earlier. ${ }^{[34]}$ This assay measures the percentage viability of the cells in response to different concentrations of the compounds. Active mitochondrial dehydrogenases of living cells convert the water soluble yellow tetrazolium salt to an insoluble purple formazan. The intensity of colour developed is an indicator of the percentage of viable cells present. In brief, cells (2000$5000 /$ well) were plated in 96-well plates and kept overnight at $37{ }^{\circ} \mathrm{C}$ after which, the cells were incubated with and without various concentrations of the compounds $(25,50$, 100 and $200 \mu \mathrm{M})$. Curcumin was used as the positive control. At the end of the incubation, medium was removed and fresh medium containing $20 \%$ MTT solution $(2 \mathrm{mg} / \mathrm{mL}$ in PBS) was added to each well and plates were incubated in at $37{ }^{\circ} \mathrm{C}$ in $\mathrm{CO}_{2}$ incubator for $2 \mathrm{~h}$. After $2 \mathrm{~h}, 0.1 \mathrm{~mL}$ of the extraction buffer ( $20 \%$ SDS in $50 \%$ DMF) was added and incubated at $37{ }^{\circ} \mathrm{C}$ for additional $1 \mathrm{~h}$ before the optical density wasmeasured at $570 \mathrm{~nm}$ using a plate reader (BioRad). The percentage of inhibition of cell viability was determined with reference to the untreated control. The data were subjected to linear regression analysis and the regression lines were plotted for the best straight-line fit. The $I_{50}$ concentrations were calculated by the respective regression analysis.

\section{RESULTS AND DISCUSSION Chemistry}

The synthetic route for the preparation of target compounds ( $\mathbf{3} \mathbf{a}-\mathbf{j}, \mathbf{4} \mathbf{a}-\mathbf{j})$ is outlined in Scheme 2. Initially, the compounds $\mathbf{1} \mathbf{a}-\mathbf{b}$ were synthesized by the reaction of 4-fluorobenzoyl/benzoyl chloride with glycine to yield 1ab (Scheme 2). On the other hand, 4-substituted phenylsulfonylpiperazines derivatives (2a-j) were prepared by starting with the appropriate arylsulfonylchlorides. 4substituted benzenesulfonylchlorides reacted with simple piperazine in $\mathrm{CH}_{2} \mathrm{Cl}_{2}$ under catalyst-free conditions. If we start with same equivalents of both piperazine and 


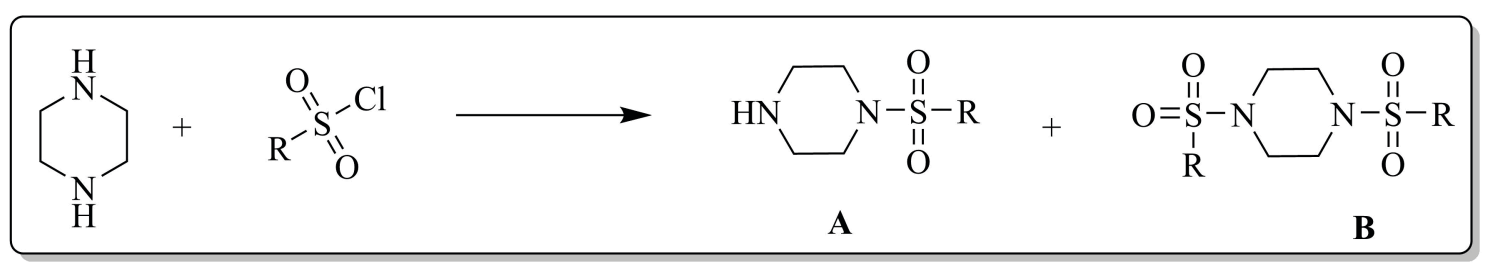

Scheme 1. Reaction of piperazine with substituted phenyl sulfonyl chorides.

benzenesulfonylchloride, we get mixture of compounds $\mathbf{A}$ and $\mathbf{B}$ were shown in Scheme 1 (confirmed by TLC, give two spots in the reaction mixture). Later we performed the reaction by taking excess amount of piperazine and keeping the temperature low $\left(0^{\circ} \mathrm{C}\right)$ most of the compound formed in this case is only $\mathbf{A}$ (confirmed by TLC, exclusively gives single spot). Now the unreacted piperazine was removed by treating the reaction mixture with saturated aq. $\mathrm{NaHCO}_{3}$ solution to afford the required product $(2 \mathrm{a}-\mathbf{j})$. Further, the structure of the compound was confirmed by ${ }^{1} \mathrm{H} N M R$, the spectrum of the compound showed a broad peak at around $\delta$ 1.50-1.60 ppm characteristic due to $\mathrm{NH}$ proton (for example for compound $2 \mathrm{a} \mathrm{NH}$ peak observed at $\delta 1.59$ $\mathrm{ppm})$. The amine functionality was also confirmed in the IR spectrum showed an absorption peak nearer to $3350 \mathrm{~cm}^{-1}$. The resultant compounds were now integrated with substituted hippuric acid in presence of coupling agents. Initially, we tried the coupling reaction with 1,1'Carbonyldiimidazole (CDI), but the product formed is found to have less yield. So we choose 1-Ethyl-3-(3dimethylaminopropyl)carbodiimide (EDCl) along with 1hydroxybenzo triazole (HOBt) to afford the title compounds. $\mathrm{EDCl}$ is known as a reagent of choice for amide coupling reactions. The use of this coupling reagent in this efficient procedure leads to a convenient process that does not require an elaborate purification. Further, the structure of all the final compounds was confirmed by NMR, mass and IR spectra. All the compounds obtained are in good yield with high purity.

\section{In Vitro Anticancer Screening}

The newly synthesized compounds $\mathbf{3} \mathbf{a}-\mathbf{j}$ and $\mathbf{4 a} \mathbf{a} \mathbf{j}$ were tested for in vitro anticancer screening by using MTT assay method. The compounds were tested against five human cancer cell lines namely, HeLa (Cervical), A549 (Lung), A375 (Skin), MD-AMB-231(Breast) and T98G (Brain) and the results are presented in the Figure 3 , whichindicate the percentage cytotoxic activity (dose dependent) of the<smiles>[R]c1ccc(C(=O)NCC(=O)O)cc1</smiles>

Scheme 2. Reagents and conditions: (a) $\mathrm{NaOH}$, Glycine; (b) $\mathrm{R}^{1} \mathrm{SO}_{2} \mathrm{Cl}, \mathrm{CH}_{2} \mathrm{Cl}_{2}, 0-10{ }^{\circ} \mathrm{C}$; (c) $\mathrm{EDCl}, \mathrm{HOBt}, \mathrm{DMF}$. 
Table 1. Cytotoxic activity $\left(\mathrm{IC}_{50}, \mu \mathrm{M}\right)^{(\mathrm{a})}$ of compounds $3 \mathrm{a}-\mathrm{j}$ and $\mathbf{4 a - j}$ against five human cancer cell lines.

\begin{tabular}{llllll}
\hline Compound & HeLa & A549 & A375 & MD-AMB231 & T98G \\
\hline 3a & $325.7 \pm 0.02$ & $462.1 \pm 0.06$ & $490.2 \pm 0.14$ & $285.7 \pm 0.03$ & $333.1 \pm 0.19$ \\
3b & $350.8 \pm 0.17$ & $230.9 \pm 0.01$ & $253.8 \pm 0.54$ & $294.5 \pm 0.38$ & $29.2 \pm 0.01$ \\
3c & $362.3 \pm 0.01$ & $302.1 \pm 0.34$ & $491.4 \pm 0.95$ & $268.8 \pm 0.02$ & $370.3 \pm 0.05$ \\
3d & $393.7 \pm 0.12$ & $763.3 \pm 0.65$ & $495.2 \pm 0.48$ & $286.5 \pm 0.01$ & $24.2 \pm 0.02$ \\
3e & $558.6 \pm 0.19$ & $497.5 \pm 0.30$ & $757.5 \pm 0.54$ & $423.7 \pm 0.14$ & $261.7 \pm 0.12$ \\
3f & $202.4 \pm 0.02$ & $262.5 \pm 0.13$ & $315.4 \pm 0.65$ & $249.3 \pm 0.17$ & $76.5 \pm 0.01$ \\
3g & $124.1 \pm 0.09$ & $244.5 \pm 0.02$ & $257.1 \pm 0.08$ & $239.8 \pm 0.12$ & $32.3 \pm 0.11$ \\
3h & $225.1 \pm 0.14$ & $216.4 \pm 0.01$ & $202.2 \pm 0.01$ & $265.2 \pm 0.90$ & $129.2 \pm 0.48$ \\
3i & $398.4 \pm 0.23$ & $301.2 \pm 0.27$ & $196.4 \pm 0.11$ & $214.1 \pm 0.59$ & $191.9 \pm 0.17$ \\
3j & $649.3 \pm 0.59$ & $478.5 \pm 0.30$ & $420.2 \pm 0.60$ & $292.4 \pm 0.16$ & $88.5 \pm 0.60$ \\
4a & $235.3 \pm 0.07$ & $216.9 \pm 0.12$ & $587.3 \pm 0.88$ & $262.4 \pm 0.50$ & $228.3 \pm 0.18$ \\
4b & $111.6 \pm 0.02$ & $211.4 \pm 0.28$ & $386.1 \pm 0.12$ & $299.4 \pm 0.34$ & $120.5 \pm 0.02$ \\
4c & $30.1 \pm 0.01$ & $113.4 \pm 0.17$ & $304.8 \pm 0.19$ & $187.2 \pm 0.83$ & $268.8 \pm 0.01$ \\
4d & $201.6 \pm 0.05$ & $214.6 \pm 0.01$ & $381.6 \pm 0.34$ & $331.1 \pm 0.65$ & $102.6 \pm 0.17$ \\
4e & $183.5 \pm 0.02$ & $231.5 \pm 0.04$ & $380.2 \pm 0.60$ & $295.8 \pm 0.01$ & $104.2 \pm 0.70$ \\
4f & $120.5 \pm 0.01$ & $326.8 \pm 0.07$ & $662.2 \pm 0.87$ & $208.7 \pm 0.09$ & $109.9 \pm 0.06$ \\
4g & $272.4 \pm 0.17$ & $113.6 \pm 0.14$ & $367.6 \pm 0.01$ & $229.3 \pm 0.04$ & $209.6 \pm 0.34$ \\
4h & $245.7 \pm 0.04$ & $87.4 \pm 0.01$ & $116.5 \pm 0.25$ & $183.5 \pm 0.33$ & $108.9 \pm 0.01$ \\
4i & $408.5 \pm 0.65$ & $343.6 \pm 0.58$ & $609.7 \pm 0.07$ & $362.3 \pm 0.05$ & $97.6 \pm 0.18$ \\
4j & $220.7 \pm 0.08$ & $231.5 \pm 0.04$ & $327.8 \pm 0.46$ & $187.3 \pm 0.01$ & $90.3 \pm 0.02$ \\
Curcumin & $17.0 \pm 0.01$ & $22.0 \pm 0.12$ & $20.0 \pm 0.01$ & $25.0 \pm 0.02$ & $12.5 \pm 0.01$ \\
\hline
\end{tabular}

(a) $I C_{50}$ values are reported in micro molar concentration of the required for $50 \%$ inhibition of cell growth was calculated and the values represent means \pm S.D. from three different experiments performed in triplicates.

synthesized compounds at concentrations ranging from 25 and $50 \mu \mathrm{M}$. The relationship between fraction of surviving cells for different cell lines and drug concentration was plotted and the response parameter $\mathrm{IC}_{50}$, which is the concentration required for $50 \%$ inhibition of cell viability was calculated. The $\mathrm{IC}_{50}$ values of the test compounds are shown in Table 1.

The obtained data revealed that most of the synthesized compounds showed potent anticancer activity against the glioblastoma cell line, T98G. Most of the compounds showed $\mathrm{IC}_{50}$ values less than 100 in T98G cell line, out of which, $\mathbf{3 b}, \mathbf{3 d}$ and $\mathbf{3 g}$ are more cytotoxic compared to other compounds. For these compounds, $I C_{50}$ values are in the range of 24.0-34.3 $\mu \mathrm{M}$ (Table 1), whereas some of the compounds showed $I C_{50}$ values less than $120 \mu \mathrm{M}$, which indicates that these compounds are also important lead compounds. Similarly in $\mathrm{A} 375$ cell line, the $\mathrm{IC}_{50}$ value of compound $4 \mathrm{e}$ is found to be $38.2 \mu \mathrm{M}$. The present study revealed that among all the tested compounds most of the compounds induce maximum cytotoxicity in the glioblastoma cells compared to cancer cells of other origins.
The MTT dose-dependent study data showed in Figure S1 (supporting information) also confirmed that, out of all the synthesized compounds, there is a substantial increase in the cytotoxicity of the compounds $\mathbf{3 b}, \mathbf{3 d}$ and $\mathbf{3 g}$ over T98G with increasing exposure to drug concentration. Further, the morphological changes induced by the compound 3d in T98G at various concentrations also correlate with that of the MTT assay results (Figure 4). The observed changes in the cellular morphologies of T98G cells under phase contrast microscope very well reflect the cytotoxic effect of the compound $\mathbf{3 d}$ in these cells. There was clear nuclear condensation, blebbing in cell membrane, decrease in the cell number and loss of the elongated morphology of T98G cells with the increase in the concentration of these compounds, as exemplified by results from studies with the compound $\mathbf{3 d}$ (Figure 4).

Among the compounds we have synthesized, the first series of benzamide derivatives (3a-j) are shown to be more potent in T98G cell line rather than other cell lines. Moreover the inhibition effect distinctively enhanced in T98G cells, when the final compounds contained $\mathrm{CH}_{3}$ and 


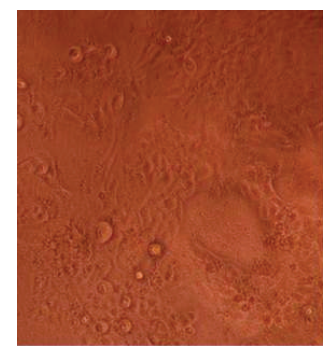

Control

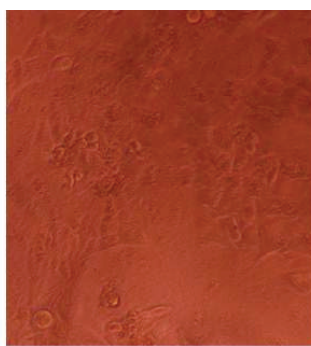

$25 \mu \mathrm{M}$

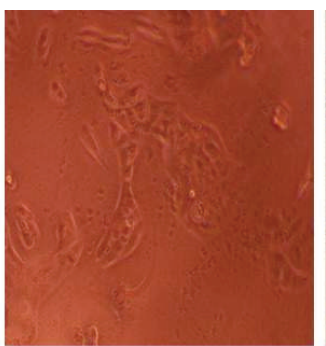

$50 \mu \mathrm{M}$

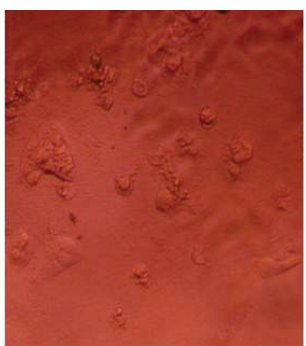

$100 \mu \mathrm{M}$

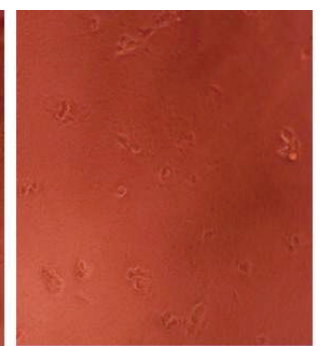

$200 \mu M$

Figure 4. Cytotoxicity of 3d against T98G (Human Glioblastoma).

$\mathrm{OCH}_{3}$ groups ( $\mathbf{3 b}$ and $\mathbf{3 d}$ ) on $4^{\text {th }}$ position of benzenesulfonylpiperazine motif. Also inhibition was substantially increased when the substitutions are flouro derivatives of methyl and methoxy viz., $\mathrm{CF}_{3}$ and $\mathrm{OCF}_{3}$.

\section{CONCLUSION}

In conclusion, synthesis of twenty novel substituted phenyllsulfonylpiperazines containing benzimide derivative has been described. All the synthesized compounds were tested against five cancer cell lines of different origins. Among the tested compounds, $\mathbf{3} \mathbf{b}, \mathbf{3} \mathbf{d}$ and $\mathbf{3 g}$ showed potent cytotoxic activity against glioblastoma cell line. Compound 3d displayed the highest cytotoxicity followed by $\mathbf{3 b}$ and $\mathbf{3 g}$. Compounds $\mathbf{4 c}$ and $\mathbf{4 e}$ were showed notable cytotoxic effect towards HeLa and A375 cell lines respectively. In general glioblastoma is the most sensitive towards the set of synthesized compounds. Some of the derivatives also inhibit HeLa and $\mathrm{A} 375$ cell lines. The results showed that the presence of $4-\mathrm{OCH}_{3}, \mathrm{CH}_{3}, \mathrm{OCF}_{3}$ and $\mathrm{CF}_{3}$ groups attached to phenylsulfonylpiperazine makes the target compounds having good cytotoxic activity. The findings from this study might be beneficial as lead compounds for designing new compounds with potential antitumor activity. A further activity profile about the synthesized compounds is under progress.

Acknowledgment. BRR is thankful to University Grants Commission (U.G.C.). MRK is thankful to the Council of Scientific \& Industrial Research (CSIR), New Delhi, India, for the award of fellowship. MSRM and BRR and MRK thank CSIR, India, for financial support under the $12^{\text {th }}$ Five Year plan project “Affordable Cancer Therapeutics (ACT)" (CSC 0301).

Supplementary Information. Supporting information to the paper is attached to the electronic version of the article at: https://doi.org/10.5562/cca3535.

PDF files with attached documents are best viewed with Adobe Acrobat Reader which is free and can be downloaded from Adobe's web site.

Conflict of Interest. The authors have declared no conflict of interest.

\section{REFERENCES}

[1] I. Jarak, M. Marjanović, I. Piantanida, M. Kralj, G. Karminski-Zamola, Eur. J. Med. Chem. 2011, 46, 2807-2815.

https://doi.org/10.1016/j.ejmech.2011.04.001

[2] C. Jin, Y. J. Liang, H. He, L. Fu, Eur. J. Med. Chem. 2011, 46, 429-432.

https://doi.org/10.1016/j.ejmech.2010.11.026

[3] Y-P. Hou, J. Sun, Z-H. Pang, et al. Bioorg. Med. Chem. 2011, 19, 5948-5954.

https://doi.org/10.1016/j.bmc.2011.08.063

[4] T. W. Loo, D. M. Clarke, J. Nat. Can. Inst. 2000, 92, 898-902. https://doi.org/10.1093/jnci/92.11.898

[5] A. Pick, W. Klinkhammer, M. Wiese, Chem. Med. Chem. 2010, 5, 1498-1505.

https://doi.org/10.1002/cmdc.201000216

[6] U. Das, H. N. Pati, A. K. Panda, et al. Bioorg. Med. Chem. 2009, 17, 3909-3915.

https://doi.org/10.1016/j.bmc.2009.04.021

[7] D. Roell, T. W. Rösler, S. Degen, R. Matusch, A. Baniahmad, Chem. Biol. Drug Des. 2011, 77, 450-459.

https://doi.org/10.1111/j.1747-0285.2011.01116.x

[8] Y. Lu, C. Li, Z. Wang, et al. J. Med. Chem. 2009, 52, 1701-1711. https://doi.org/10.1021/jm801449a

[9] J. Zhang, P. L. Yang, N. S. Gray, Nat. Rev. Cancer 2009, 9, 28-39. https://doi.org/10.1038/nrc2559

[10] A. J. Kraker, C. A. Mizzen, B. G. Hart, et al. Mol. Can. Ther. 2003, 2, 401-408.

[11] A. Lu, H. Luo, M. Shi, et al. Bioorg. Med. Chem. Lett. 2011, 21, 4924-4927. https://doi.org/10.1016/j.bmcl.2011.06.001

[12] A. S. Aboraia, S. W. Yee, M. S. Gomaa, et al. Bioorg. Med. Chem. 2010, 18, 4939-4946. https://doi.org/10.1016/j.bmc.2010.06.011

[13] Y. Li, Y. Zhou, P. Qian, et al. Bioorg. Med. Chem. Lett. 2013, 23, 179-182.

[14] W. Mao, M. MengmengNing, Z. Liu, et al. Bioorg. Med. Chem. 2012, 20, 2982-2991.

https://doi.org/10.1016/j.bmc.2012.03.008 
[15] F. Fiorino, M. Eiden, A. A. Giese Severino, et al. Bioorg. Med. Chem. 2012, 20, 5001-5011. https://doi.org/10.1016/j.bmc.2012.06.026

[16] A. Casini, A. Scozzafava, A. Mastrolorenzo, L. T. Supuran, Curr. Can. Drug. Targets 2002, 2, 55-75. https://doi.org/10.2174/1568009023334060

[17] S. S. Ahmad Shah, G. Rivera, M. Ashfaq, Mini-Rev. Med. Chem. 2013, 13, 70-86. https://doi.org/10.2174/138955713804484749

[18] R. J. Liu, J. A. Tucker, T. Zinevitch, et al. J. Med. Chem. 2007, 50, 6535-6544. https://doi.org/10.1021/jm070650e

[19] A. Shaabani, E. Soleimani, A. H. Rezayan, Tetrahedron Lett. 2007, 48, 2185-2188. https://doi.org/10.1016/j.tetlet.2007.01.091

[20] S. Kirby, S. Z. Gertler, W. Mason, et al. NeuroOncology 2005, 7, 183-188. https://doi.org/10.1215/S1152851704000602

[21] A. M. Mauer, E. E. P. C. Cohen Ma, M. F. Kozloff, et al. J. Thoracic Oncology 2008, 3, 631-636. https://doi.org/10.1097/JTO.0b013e318174e01f

[22] A. W. Shaw, C. Y. Chang, M. Y. Hsuet al. Eur. J. Med. Chem. 2010, 45, 2860-2867. https://doi.org/10.1016/j.ejmech.2010.03.008

[23] D. Kommula, S. Polepalli, N. Jain, M. S. R. Murty, Indian. J. Pharm. Sci. 2018, 80 (5), 930-939. https://doi.org/10.4172/pharmaceutical-sciences.1000440

[24] L. Wang, T. Wang, B. Yang, Z. Chen, H. Yang, Med. Chem. Res. 2012, 21, 124-132. https://doi.org/10.1007/s00044-010-9512-1

[25] B. J. Henderson, D. J. Carper, T. F. G. Cestari, et al. J. Med. Chem. 2011, 54, 2011, 8681-8692.

https://doi.org/10.1021/jm201294r

[26] M. E. Prime, O. A. Andersen, J. J. Barker, et al. J. Med. Chem. 2012, 55, 1021-1046.

https://doi.org/10.1021/jm201310y

[27] B. R. Rao, M. R. Katiki, K. Dileep, et al. Lett. in Org. Chem. 2019, 16 (9), 723-734.

https://doi.org/10.2174/1570178615666181113094539

[28] D. Sun, Z. Wang, M. Cardozo, et al. Bioorg. Med. Chem. Lett. 2009, 19, 1522-1527.

[29] M. S. R. Murty, B. R. Rao, K. R. Ram, et al. Med. Chem. Res. 2012, 21, 3161-3169.

[30] M. S. R. Murty, B. R. Rao, K. M. Rao, R. N. Lekshmi, R. J. Anto, Med. Chem. Res. 2013, 22, 4980-4991. https://doi.org/10.1007/s00044-013-0510-y

[31] K. Dileep, S. Polepalli, N. Jain, et al. Mol. Divers 2018, 22 (1), 83-93. https://doi.org/10.1007/s11030-017-9795-y

[32] K. M. Rao, K. Dileep, S. Polepalli, N. Jain, M. S. R. Murty, Lett. Drug Des. Discov. 2019, 16 (8), 846860.

https://doi.org/10.2174/1570180815666180621100314

[33] D. Kommula, K. Mohana Rao, B. Ramalingeswara Rao, et al. Org. Commun. 2017, 10 (3), 178-189.

[34] V. B. Smitha, T. P. Vineshkumar, A. Deepti, et al. J. Biol. Chem. 2005, 280, 6301-6308. https://doi.org/10.1074/jbc.M410647200 